2017-06-28

\title{
Disability, social inclusion and the marketing of tourist attractions
}

\section{Cloquet, I}

http://hdl.handle.net/10026.1/10048

10.1080/09669582.2017.1339710

Journal of Sustainable Tourism

Informa UK Limited

All content in PEARL is protected by copyright law. Author manuscripts are made available in accordance with publisher policies. Please cite only the published version using the details provided on the item record or document. In the absence of an open licence (e.g. Creative Commons), permissions for further reuse of content should be sought from the publisher or author. 
"This is the author's accepted manuscript. The final published version of this work (the version of record) is published by Taylor \& Francis Group in the Journal of Sustainable Tourism [28 June 2017] available at: http://dx.doi.org/10.1080/09669582.2017.1339710. This work is made available online in accordance with the publisher's policies. Please refer to any applicable terms of use of the publisher."

\section{Disability, social inclusion and the marketing of tourist attractions}

Abstract: The participation of persons with a disability (PWDs) in tourism has received growing academic interest in recent years. This paper contributes to a reflection on how accessible tourism relates to the sustainable development paradigm. To investigate this relationship, it goes beyond the question of PWDs' access to tourism services, and adopts an inclusiveness perspective. Inclusion is examined in terms of legislation, marketing and imagery, and representations of PWDs as consumers embedded within social units-and families in particular. These dimensions are explored empirically in a study of visitor attractions in Cornwall (England) based on a quantitative and qualitative content analysis of brochures and websites. The study shows that the marketing materials of Cornish visitor attractions mainly focus on access, and the imagery used largely projects quasi invisibility or provides ambiguous messages. Communication with PWDs rarely addresses the family unit, making the family tourism experience intangible in the pre-trip phase. These results point at weaker implementation of inclusiveness, which corroborates previous findings of watered down definitions of rights to tourism under neo-liberal ideologies and economic crises. The paper discusses implications for social inclusion and highlights avenues for future research.

Keywords: disability, marketing, inclusive society, family tourism, accessible tourism, imagery 


\section{Introduction}

There has been growing research interest in the participation of persons with a disability (PWDs) in tourism in recent years. This has been driven by two non-exclusive approaches: one examines disabling and enabling factors in the industry and their effects on PWDs' tourism experience and wellbeing (e.g., Stumbo \& Pegg, 2005; Yau, McKercher \& Packer, 2004); the other considers PWDs in terms of their role as consumers and their potential as an under-developed market niche (e.g. Darcy, Pegg \& Cameron, 2011; Domínguez Vila, Darcy, \& Alén González, 2015). The latter economic and neoliberal perspective can be perceived as an attempt to make the case for accessibility in the tourism industry within a context where institutionalisation through legislation has generally failed. However, It has undoubtedly helped put the accessibility within tourism on the research and political agenda. More recently some authors have advocated that accessible tourism be embedded in a sustainable development paradigm notably by using a triple-bottom line framework (e.g., Darcy, Cameron, \& Pegg, 2010). However, it is argued in this paper that reflection on disability in tourism needs to go beyond the question of PWDs' access to tourism venues and services, and embrace an inclusiveness perspective.

The aim of this paper is to examine the extent to which the tourism industry has adopted an inclusive approach to accessibility, and more particularly as regards marketing practices. Closely related to the social development dimension of sustainability (Vallance, Perkins, \& Dixon, 2011), the concept of social inclusion is defined as a process toward a society in which every individual has an active role to play (UNDESA, 2007). It aims to lower economic, social and cultural boundaries and embrace diversity, notably by acting on the following dimensions: making sure that everyone is recognized in society (visibility), has one's concerns and needs taken into account in policy-making, is given access to social interactions, and enjoys rights and resources enabling a full participation in society (UNDESA, 2007). Therefore inclusiveness encompasses the provision of access whilst being broader in scope as it includes aspects relating to identity and social cohesion.

More specifically, the paper assesses how these dimensions are incorporated in the marketing of visitor attractions in Cornwall, England, by analysing their promotional materials, notably their websites and tourism brochures. This is achieved by focusing on three specific objectives: (1) to determine what aspects of PWDs' inclusion in, and right to, tourism are reflected in such materials, and how the content of this material is affected by the characteristics of attractions (i.e., the type, size, and legal status) ; (2) to examine how PWDs are portrayed in text and images, and what can be inferred from such representations in terms of PWDs' social inclusion in tourism; (3) to explore access of PWDs to social interactions in tourism by examining how families with a member who has a 
disability (FMDs) are represented on the websites of visitor attractions known for their attractiveness to families (i.e., determine whether visitor attractions that target families consider FMDs in their communications, and, if so, identify how FMDs are portrayed and communicated with).

The specific attention paid to marketing, visitor attractions and FMDs rests on the following logical development. Marketing is crucial in enabling PWDs' participation in tourism as it is the first contact point when attempting to access activities either on holiday or when planning a day trip. Visitor attractions are often key motivators for visiting a destination, and have relatively high economic and social incentives for improving their accessibility as their market is composed of overnight and day visitors, including local residents (Leask, 2010). However, they have received much less attention in the study of accessible tourism. The adoption of a family perspective in the third objective of the paper rests on the role the family plays as a major social institution and in influencing PWDs' tourism participation and experience (Blichfeldt \& Nicolaisen, 2011; Foggin, 2011; Yau et al., 2004).

\section{Disability, Rights to tourism and Accessibility}

The UN Convention on the Rights of People with Disabilities - which came into force in 2008-and its 165 Parties and 160 Signatories recognize the right of PWDs to take part on an equal basis with others (i.e. 'able-bodied') in leisure, recreation and tourism. To enable such participation, States Parties shall take appropriate measures to ensure that PWDs "have access to sporting, recreational and tourism venues; [and] to services from those involved in the organization of recreational, tourism, leisure and sporting activities" (UN General Assembly, 2006, Article 30). As stated in the convention, PWDs' rights to tourism are contingent on the level of rights to tourism enjoyed by non-disabled people. Even in countries in a tertiary stage of economic development, in which tourism is considered a social norm, this level of right is dependent upon the priorities of governments and states; and in times of global economic crisis and spread of neoliberalism, the debates surrounding the rights to tourism have progressively shifted to discourses seeking to legitimize access to tourism from an economic perspective (McCabe \& Diekmann, 2015). Similar discourses are encountered with regard to PWDs' access to tourism venues and services as such rights are generally confined to the availability of resources (e.g., UNWTO, 2016, Article 4), as is the case in the UN convention.

In such discourses, disability is often considered in terms of access needs, which have been categorized in different dimensions, including mobility, hearing, vision, cognitive/learning, mental health, and sensitivities and long-term health conditions (e.g., dexterity loss, fatigue) (Darcy et al., 2010). Such differentiation between access requirements has been critical to identify environmental barriers affecting PWDs' access to tourism goods and services (Stumbo \& Pegg, 2005; Darcy \& Buhalis, 2011). 
However, subsuming disability to access needs comes with a risk of misrepresenting the higher complexity of developing inclusive tourism practices. Indeed, it is acknowledged that PWDs are statistically more likely than able-bodied people (ABPs) to live on lower income, exposing them to higher levels of financial constraints (Figueiredo, Eusébio, \& Kastenholz, 2012; Veitch \& Shaw, 2011). Moreover, each of the dimensions above encompasses a variety of medical conditions which may have specific requirements in terms of inclusion. Also psycho-social factors including feelings of being different to ABPs can affect the participation of PWDs in tourism (Kastenholz, Eusébio, and Figueiredo, 2015).

The case of the UK, and Cornwall in particular, is a good illustration of this complexity. The level of right to tourism in the UK has important implications for the Cornish tourism industry given that $94 \%$ of Cornwall visitors are British nationals (Beautort Research, 2013). The right to holidays with pay is enshrined within the employment legislation, hence directly linked to workers' rights. This can be regarded as a barrier to inclusive tourism as working-age PWDs are still less likely to be in employment than ABPs, with a percentage point gap up to 30.1 in 2012 (i.e. over 2 million people) (Office for Disability Issues, 2014). Related to this is the higher likelihood for PWDs to live in a household with lower income. In 2012 19\% of individuals in FMDs lived in relative income poverty in the UK-on a before housing costs basis-compared to $15 \%$ of individuals in families with no disabled member (Office for Disability Issues, 2014). Such barriers to tourism participation have been addressed to a certain extent by some visitor attractions which offer concessions for PWDs and sometimes their carer, and by the third sector that has developed social tourism holiday schemes available to PWDs (Hunter-Jones, 2011). Such schemes, however, usually target those with a severe disability as a consequence of their lower purchasing power and the lower level of adaptation of the tourism sector to their medical condition, e.g. those with learning disabilities (Hunter-Jones, 2011).

Regarding accessibility, the UK introduced the Disability Discrimination Act (DDA) in 1995. Before then-with some evidence in the 1980s - a number of PWDs reported a feeling of being unwelcome at some mainstream tourism facilities (Couch, Forrester, \& Mayhew-Smith, 1989). The DDA included requirements pertaining to business places (e.g., access, facilities and equipment) as well as advertising. However, the requirement of reasonable adjustments to buildings to remove physical barriers to access led to much avoidance with businesses stating the required adaptations were beyond their resources or were impractical; this is despite the fact that they had to prove such modifications had been considered (Shaw \& Veitch, 2011). Equal access to tourism facilities was introduced, as a specific requirement almost a decade later, in 2004 (Barnes \& Mercer, 2010). Before 
2004, tourism was rarely targeted to PWDs except through 'special needs' activities which reinforced that their needs were different to those of the non-disabled (Murray, 2002).

In 2010, the UK adopted the Equality Act, which was brought in to protect certain groups of the population, like PWDs, who are at risk of being discriminated against (Equality and Human Rights Commission, 2010). However, the Equality Act has been criticized by some for having watered down the rights provided by the DDA, and many businesses were found to be reluctant to adapt to the new changes, and tended to ignore legal constraints and the specific needs of PWDs. In such a context, some authors, including Barnes and Mercer (2010), see fully accessible and inclusive environments as being a long term goal.

\section{Tourism marketing and socialization}

For PWDs who are likely to travel, barriers to access need to be addressed across the supply-chain, and in all phases of the tourism experience: before, during and after the trip. In the pre-trip phase, which is the core focus of this paper, the availability, accessibility and reliability of information on access is often a prerequisite for participation in tourism and destination selection (Blichfeldt \& Nicolaisen, 2011; Yau et al., 2004). Families and friends and the internet have been identified as key information sources, with the latter being less used by people with a learning disability (Figueiredo et al., 2012). A web page is deemed accessible if it can be handled by the use of assistive technologies (Pühretmair \& Nussbaum, 2011; Michopoulou \& Buhalis, 2011; UNWTO, 2016), and centralizes all access information in one specific section clearly signposted from the homepage and reachable from most other sections of the website, and the family or multigenerational pages in particular (Visit England, n.d.a). In terms of content all dimensions of access needs should be addressed, and information should include geography and terrain, experiences offered to PWDs, car parking, access to toilets, café, restaurant and shop, and available assistance during the visit (Visit England, n.d.a).

According to Goossens (2000), taking part in tourism activities depends on a decision-making process that includes two modes: 'information processing' and 'affective choice'. Tourism marketing that caters for both modes would ease decision-making. The former mode is utilized to evaluate the qualities of products and services based on criteria such as price, facilities and service quality. PWDs will thus use this mode to assess access information discussed above alongside other elements that include pricing policy. The latter mode consists of a preference for some attributes of the activity or place, based on marketing, textual and visual images. In order to elicit a positive reaction from the intended audience tourism advertising is presented in a way that means something to such an audience (Goldman, 1992; Gretzel, Yuan, \& Fesenmaier, 2000). This involves the use of 
representational techniques that symbolically transform reality (Xiang, Wöber, \& Fesenmaier, 2008), and that have been blamed for reinforcing negative assumptions, beliefs and values about those who are not part of the targeted audience (Borgerson \& Schroeder, 2002).

The socio-cultural importance of images has been under discussion for some time, with tourism marketing materials being considered as using socially defined attributes to convey their messages in a visual format (Dann, 1996). Imagery has the ability to influence people's opinions, restricting and changing mindsets (Decrop, 2002; MacCannell, 1976; Morgan \& Pritchard, 2000). Therefore, investigating the potential meanings conveyed in tourism imagery is of importance when analysing the discourse of tourism providers. Previous research into tourism discourse has shown how central the body has been in Western tourism supply and consumption, pointing to the role of the tourism industry in shaping social representations regarding the body and beauty (Small \& Darcy, 2011). It was shown by Edelheim (2007) that bodies with a visible disability were under-represented in mainstream tourism imagery, leaving a sense of an 'invisible minority' (Nelson, 1999).

Such a situation has also been observed in mainstream media that either exclude PWDs or portray them as either a cause for inspiration or an object of pity (Barnes \& Mercer, 2003). In 1993 Shapiro contended that these projected images were internalized by PWDs and ABPs alike, leading to social stereotypes, discrimination and minority status contented by a number of PWDs. In the meantime representations of PWDs, including children, in mainstream media have gradually evolved toward more-but still not fully-realistic representations of lived experience (Lawlor \& Elliot, 2012).

Whilst not being represented within tourism media is seen as a disabling factor (Shaw \& Veitch, 2011), it can be argued that being represented in an inclusive manner may help develop a sense of belonging and acceptance (Edelheim, 2007). Some researchers believe that children and young adults are receptive to characters with somewhat comparable bodies, and may develop a more positive body image from representations that depict such characters in a positive yet realistic way (Lawlor \& Elliot, 2012). More recently this seems to have been recognised by some tourism professionals. An example is Visit England (n.d.a, b) which advised that tourism advertising should include photographs of a diversity of visitors - not only in the access section but throughout the advertising medium -along with testimonials from PWDs, with the aim to raise confidence to visit amongst this market segment. There is currently a lack of knowledge of whether the projection of such inclusive imagery goes hand in hand with improved accessibility in the tourism industry.

PWDs, tourism and the role of family 
Decisions regarding holidays are rarely made by individual consumers, rather by members of a decision-making unit (Blichfeldt, 2008). The pivotal role of the family with regard to PWDs' participation in tourism has been highlighted in the literature (Blichfeldt \& Nicolaisen, 2011; Darcy et al., 2010; Yau et al., 2004). In their study of tourism and PWDs in Portugal, Figueiredo et al. (2012) found that $77 \%$ of their sample travelled with their family. Although these authors pointed out that this situation was not necessarily desired by the PWDs themselves, it should be noted that children with disabilities who were aged under 14 years were not included in their study. Moreover, single adults were over-represented in their sample, accounting for $75 \%$ of the total number of respondents. This contrasts with 2012 demographic figures on disability in the European Union (27 countries), which showed that $30 \%$ of PWDs lived with a partner as a couple without children, and a further $22 \%$ lived in households with children, as a couple (12.9\%), as a single parent (2.9\%), or living with an adult who has children (6.4\%) (Eurostat, 2012).

As in the case of other families, FMDs tend to consider family tourism as being more than an act of consumption, attributing social value to it, and perceiving it as being an invaluable source of benefits and improved quality of life. Family tourism is indeed deeply embedded in Western societies, and within the UK in particular where it has roots dating back to the late 1800s (Southall, 2012). Tourism is valued by many as a tool in children's education and cultural development (Southall, 2012), with similar findings concerning FMDs (Foggin, 2011). Moreover, there is growing evidence that PWDs can derive psychological, physical and social benefits from leisure travel (Burns, Paterson, \& Watson, 2009; Conradson, 2005; Pagán, 2015). In this regard, it may be hypothesized that tourism can be one of these beneficial developmental experiences, referred to by Lawlor and Eliott (2012), that families and children with a disability work towards, fostering self-understanding and positive body images.

Benefits are also to be found at the family level as family leisure activities associated with tourism provide opportunities for interaction and communication among family members. Such opportunities are deemed particularly important in improving family functioning (Lehto, Choi, Lin, \& MacDermid, 2009; Smith, Freeman, \& Zabriskie, 2009) in a contemporary society that has placed increased pressures on family time (Huff, Widmer, McCoy, \& Hill, 2003). There are indications of positive relationships between quality time spent as a family and positive family outcomes of increased communication, improved satisfaction in marital relationships, greater feelings of satisfaction with family life along with improved family cohesion and adaptability (Agate, Zabriskie, Agate, \& Poff, 2009; Huff et al., 2003; Lehto et al., 2009; McCabe \& Johnson, 2013; Smith et al., 2009; Zabriskie, 2001; Zabriskie \& McCormick, 2001, 2003). 
Based on these benefits, and in line with Dowling and Dolan (2001), we stress the need for a whole family perspective to disability in tourism research. With regard to marketing to FMDs, we can assume that it not only involves marketing accessibility but also family-oriented experiences. Concerning access information, it has been recognised that such families may dismiss certain tourism experiences if marketing fails to reflect accessibility and inclusion (Foggin, 2011; Scholl, McAvoy, Rynders, \& Smith, 2003; Veitch \& Shaw, 2004). Foggin's work underscores the importance of access information for the whole family, and the additional pressure it represents for a parent with a disability, arguing that:

\footnotetext{
"Not having an activity happen as planned puts a damper on the enjoyment of the day. It is especially hard when there are children 'that have had a disappointing afternoon or we haven't gone somewhere just because of the wicked old stepmother in a wheelchair"' (Foggin, 2011, p. 112).
}

There is however little research on how FMDs are or should be included in tourism marketing strategies. Literature on family tourism might give some indicative suggestions although it is not known to which extent such knowledge applies to FMDs. Such literature highlights the role of children in family holiday dynamics, and the influence of children's age categories. Children are seen as a driver of the decision-making process (Page \& Connell, 2009 as cited in Southall, 2012, p.57), with children's ages impacting on the types of holidays that will be selected. Another critical aspect with possible implications for marketing to FMDs is that collective intentionality does not preclude parents and children's aspirations to spend time on their own and with their peers (Schänzel \& Smith, 2013). Motives may diverge with relaxation being amongst parents' primary motives while children are more likely to seek activities and fun, especially as they get older (Schänzel, 2012). These diverging wishes need to be adequately addressed by the parents and tourism providers, if additional stress is to be avoided (Schänzel, 2012). This is even more critical for FMDs whose daily stresses and strains tend to be demanding both physically and emotionally.

\section{Disability in online and paper marketing of visitor attractions in Cornwall}

The English county of Cornwall was selected as the study area for this research as it is one of the key tourism destinations in England with approximately 4 million visitors a year (Visit Cornwall, 2014). Cornwall is located in the far South West of England with the coastline stretching around the county for almost 300 miles. It offers a wide variety of visitor attractions. In 2012 the Cornwall visitor survey, conducted annually with over 1,000 participants, found that $22 \%$ of respondents had a PWD travelling with them, and $24 \%$ visited the region with their children (Beautort Research, 2013). In addition, 21\% of the population of Cornwall are classified as having a disability (http://www.disabilitycornwall.org.uk, 2017), making it vital that the tourism industry within the area considers the needs of both the locals 
and tourists by providing accessible, inclusive facilities and attractions for local and visiting FMDs. Cornwall was thus not chosen for its representativeness of other destinations in England, but as a case outside major urban areas, and with relatively strong economic and social incentives to enhancing accessibility.

\section{Methodology}

The study consisted in a content analysis of the texts and images of brochures and websites. The analysis was restricted to these mediums due to time and budget constraints; such mediums were identified in the Cornwall visitor survey for being primary sources of information for visitors. Paper brochures are a popular information source for tourists once in the destination area, with $51 \%$ survey participants reporting collecting information on places and attractions to visit and things to do (Beautort Research, 2013), whilst PWDs' preference for the internet-provided that websites are accessible-was highlighted earlier in the paper. The methodology consisted of two types of content analysis. One was quantitative and was performed in 2014-2015. Its main focus was on accessibility, but it also included some aspects of representation in imagery. The second was qualitative. It was conducted in 2016 and aimed to gain critical insights into how PWDs and FMDs were addressed in the marketing of visitor attractions.

The quantitative content analysis consisted in a descriptive approach and a Pearson's chi-square test on a sample of 100 brochures and 175 websites. Visitor attractions were included in the study only if they advertised for both locals and tourists both on paper and/or online. Concerning the brochures, an exhaustive approach was adopted in that brochures were retrieved from all tourist information offices (see list provided in www.visitcornwall.com/essentials/visitor-information-centres) and most information points ${ }^{1}$ in Cornwall. Brochures advertising multiple places were omitted due to the very limited detail about each attraction.

The websites were identified using a method similar to that employed by Choia, Lehto and Morrison (2007) and Govers and Go (2005). The internet was searched with the Google UK search engine, and with Google's Custom Search Application Programming Interface (API), which enabled an automated search. The API serves as an interface between software programmes and facilitates their interaction, similar to the way in which the user interface facilitates the interaction between humans and computers (Google, 2012). The search was restricted to Google as it remains the most popular search engine (Purcell, Brenner, \& Rainie, 2012). It was done with the keywords 'tourist attraction', 'leisure

\footnotetext{
${ }^{1}$ Note that some businesses regularly update and change their brochures and this occurred during the collecting and coding phase, however, although the newer brochures were not considered here, a short examination of them did show any differences in the key contents under investigation.
} 
facility', 'sport', 'outdoor recreation' and 'place to visit' combined with 'Cornwall', reflecting users' preferences for short and very general queries (Xiang, Gretzel, \& Fesenmaier, 2009). This yielded more than $2,000,000$ results, from which it was decided to keep the first 200 for further analysis. Such a sample size was deemed a reasonable comparison to the 100 brochures, and in line with previous findings on the duration of a typical web session and the number of result pages likely to be navigated through by online travel information searchers (Pan, Xiang, Law, \& Fesenmaier, 2011). From this list, 52 websites were removed as they did not advertise for both locals and tourists. The list was then cross-validated by comparing it manually with three lists of popular Cornish attractions available online (i.e., Wikipedia's list of museums in Cornwall, the Great Gardens of Cornwall, things-to-do list provided by Cornwall Online) to make sure the most popular attractions were not missed. This led to the inclusion of a further 27 websites, leading to a final sample of 175 websites.

The instrument used for data collection included two sections. One section aimed at assessing accessibility and PWDs' inclusion in the marketing mediums under consideration. It was comprised of the following categorical variables representing the presence or absence of: (a) information items about accessible parking, toilets, specialist equipment, and any other element, (b) concessions for PWDs, (c) icons relating to accessibility, (d) information on the level of access (such level is typically referred to by the promoter as no, limited, majority and full access), and (e) reference to disability in narratives and imagery. The second section looked into some characteristics of the organisations that owned and managed the visitor attractions under scrutiny.

The objective of this section was to identify possible relationships between organisational features and the marketing of accessibility. One variable was the type of visitor attraction, which included four categories based on those found in the Cornwall Visitor Survey (Beautort Research, 2013): (a) gardens and natural environment, (b) themed attractions, (c) physical activity, sports and outdoor recreation, and, (d) arts, entertainment, museums and heritage. Another variable was the size of the organisation, which was determined based on the number of employees following the definition of the European Commission (2016): Small, with less than 50 employees; Medium, whose employee numbers are between 50 and 250; Large, with more than 250 employees. A third variable was the legal status of the organisation that distinguished between commercial businesses and charities. Due to time constraints, the coding of the second and third variables essentially relied on the information available on the promotion material under analysis. The information was found for most visitor attractions included in the study but not for all, resulting in samples of 96 brochures and 151 websites for the variable size and 90 brochures and 157 websites for the variable legal status. 
The qualitative content analysis was designed to complement the data obtained with the quantitative approach, and more particularly to explore how PWDs and FMDs were represented on the websites of popular visitor attractions well-known for targeting families. Based on the results of our quantitative analysis, it was decided to focus on medium to large sized organizations. These were found to be more likely to communicate about accessibility and to provide more information. Both profit-driven organisations and charities were included in the analysis. In accordance with the saturation principle, the analysis stopped when there was a reliable indication that the themes identified hitherto would not change profoundly with the inclusion of additional websites. In total eight websites were content analysed, four charities and/or social enterprises, and four profit-driven companies. They represented $11 \%$ of websites which communicated on more than one measure of accessibility.

The four charities included the Eden Project, the National Trust's Lanhydrock estate, Newquay Zoo and the Trebah Garden. The Eden Project is operated by 'The Eden Trust'. It is a 13-ha site that illustrates human dependence on plants and other natural resources to develop resilient individuals, communities and societies (www.edenproject.com, 2016). It is visited by approximately one million visitors a year (ALVA, 2016). Lanhydrock is a 0.4-ha wooded estate with a listed Victorian country house and gardens (www.nationaltrust.org.uk/lanhydrock, 2016). Owned and managed by the National Trust Lanhydrock is visited by 240,000 people a year (ALVA, 2016). Newquay Zoo is part of South West Environmental Parks Ltd, and is home to a sizeable number of rare and endangered species with 5 hectares of tropical gardens (www.newquayzoo.org.uk, 2016). It attracts around 160,000 visitors a year. Trebah Garden is run by a small trust with less than 30 employees (Charity Commission, 2016). Based on the revenues it derived from entrance fees (see financial accounts published by the Charity Commission, 2016), it has an estimated 60,000 visitors a year.

Among the commercial businesses were two theme parks, a landmark destination, and a botanical garden. Part of Camel Creek Ltd, Camel Creek Adventure Park is a 44-ha theme park that interprets the legends of the area and attracts around 200,000 visitors a year. Flambards is an amusement park that has been in operation for forty years; it offers rides and indoor attractions such as a life-size Victorian village and an experience of Britain in the Blitz. In 2016 it was owned by Livingstone Leisure Ltd. No information was found on its visitor numbers (www.flambards.co.uk, 2016). The landmark destination under scrutiny is Land's End. It is owned and managed by the commercial company Heritage Great Britain PLC that manages several natural sites of outstanding beauty in the UK. 'Land's End' receives more than 400,000 visitors each year (www.landsend-landmark.co.uk, 2016). The fourth private company is the Lost Gardens of Heligan, one of the major attractions in Cornwall with 220,000 
visitors a year (Visit England, 2015), which is a botanical garden that was fully restored in the 1990s (www.heligan.com, 2016).

Data were collected and analysed by a single researcher using an analytical grid (see Table 1) which was applied to the texts and images of the homepage and section(s) devoted to accessibility and family-oriented services. Images were analysed using the social semiotic approach (Kress \& van Leeuwen, 1996). Social semiotics is one of the techniques developed to examine the meanings of visual representations, along with visual semiotics (Barthes, 1973) and iconography (Panofsky, 1970). It considers the social dimension of sign-making by studying their meaning potential within their context of use. Meaning potentials are determined based on socially created networks of options, which are framed by past rules or best practices (e.g. based on visual art theories, psychological theories of perception), users' interests, social beliefs and relationships of power (van Leeuwen, 2005). Applying social semiotics is particularly meaningful in this study as its use has been advocated in critical research, that is, to ask questions relating to the meanings conveyed in images (Jewitt \& Oyama, 2001).

Each image was systematically described based on dimensions developed in social semiotics (Jewitt \& Oyama, 2001). The dimensions relate to three meta-functions through which potential meaning is circulated in visual images, namely: (1) the representational meaning is derived from the way people and places of things are depicted, along with how each element is portrayed (e.g. presence of symbolic attributes) and how elements relate to each other spatially in the image (connections between elements through lines, visual rhymes of colour, shape); (2) the interactive meaning refers to the particular relations that are created between the picture frame and the viewers; this meaning is produced by three factors, including contact (through looks, facial expressions, gestures), distance (through the size of frame, with a continuum between close-up and full figure) and point of view (through angle and frontality); and (3) the compositional meaning is derived from the placement each element is given in a composition, whether elements are given separate identities or represented as belonging together with connections between them, whether some elements are made more eyecatching than others, and how true to reality the whole composition may be thought of (Jewitt \& Rumiko, 2001).

[Insert Table 1 around here]

\section{Aspects of accessibility and inclusion marketed by visitor attractions}

With only $44 \%$ of the brochures and $56 \%$ of the websites (98 of 175 ) in the study providing information on accessibility, our results tend to support Barnes and Mercer's (2010) views that, despite PWDs' 
rights being recognised in legislation since 1995, providing fully accessible and inclusive environments remains a long term goal. Moreover, when accessibility was marketed this tended not to be done in a comprehensive manner. However, the variety of information provided on accessibility differed greatly between advertising mediums. Among the brochures which communicated on accessibility, 38\% (i.e., 17 units) provided information on more than one category of measures associated with disability (e.g. parking, toilets, concessions); this proportion reached $71 \%$ for websites (i.e., 70 units). This implies that communication on accessibility was limited to one single need in $62 \%$ of brochures and $29 \%$ of websites.

Access was addressed in $56 \%$ of brochures and $69 \%$ of websites, with $27 \%$ of brochures and $35 \%$ of websites advertising that the attractions were accessible in full or major part. The percentage of advertising materials stating that no access was provided to PWDs was $4 \%$ for each medium. Toilets and parking adapted to the needs of PWDs were considered respectively in $42 \%$ and $39 \%$ of the websites, which was twice as much as in brochures (24\% and $18 \%$ ). Half of online advertising specified that they offered specialist equipment for PWDs, this plummeted to $11 \%$ for brochures. Information about concessions to PWDs was provided in just $7 \%$ of brochures and $19 \%$ of websites.

The data were then tested for associations between the provision of access information and variables related to the visitor attractions. As is shown in Table 2 the proportions of brochures and websites with at least one information item on access to PWDs were found to be similar across the four categories of attractions, with some higher scores for 'Gardens and Natural Environments'. However, this finding needs to be considered with caution as the representativeness of this category in both mediums was lower than expected in an area renowned for its countryside, beaches and gardens (Visit Cornwall, 2014). Table 3 shows the positive correlations highlighted with the chi-square tests. Organization size was significantly associated with the provision of access information, suggesting that small businesses are less likely to market accessibility than medium and large companies (both online and paper, $p=0.01$ ). It was also found that larger businesses were more incline to use a more comprehensive approach (both online and paper, $p=0.01$ ). Charities were more likely than profitdriven businesses to consider accessibility within online advertising $(p=0.01)$, and to provide information about a variety of needs (both online and paper, $\mathrm{p}=0.05$ ).

[Insert Table 2 around here]

Textual and visual representations of PWDs in the marketing of visitor attractions 
The quantitative analysis confirmed that the under-representation of PWDs in online marketing remains a topical issue. The textual analysis pointed that the term 'special needs' was still used by some visitor attractions despite criticisms for its emphasis of the differences between PWDs and ABPs, with the latter assumed as being the norm (Murray, 2002). PWDs were also poorly represented in imagery, with no image of PWDs found in the paper format and just six images (4\%) and one video (with still images) in the 175 websites under scrutiny. The qualitative analysis provided similar results. Although the eight websites had a section devoted to accessibility, the amount of information they delivered was variable. There were also very few images portraying PWDs. The cases of the Eden Project, Trebah Garden and the Lost Gardens of Heligan are discussed in more detail as these had websites that developed accessibility more thoroughly than the other attractions.

The Eden Project was the only attraction with a comprehensive approach to accessibility, reflecting the diversity of disability with issues relating to mobility, vision, hearing and sensory impairments as well as dietary requirements. Its accessibility guide was also the only one to highlight the fun and learning experience PWDs may have onsite rather than focusing on constraints. Hindrances were addressed by giving facts (e.g., steep gradients, length of paths) and proposing alternatives (e.g. tactile map). The Eden Project's multidimensional way of marketing accessibility may be associated with its collaboration with the Sensory Trust, a charity committed to creating accessible and engaging outdoor experiences (www.sensorytrust.org.uk, 2016). The Eden project, Trebah Garden and Land's End organized the information following an access chain perspective that addresses the different needs before and during the visit, centralizing all information in a structured manner. The Lost Gardens of Heligan provided very detailed guidance to wheelchair users, covering path gradients, width, cross slopes, ground surface and weather effects and rest places.

Images of PWDs were only displayed by two of these visitor attractions which differed in their approaches to representing disability visually. The images contained in the Trebah Garden website centred on mobility with three images of an older lady on a motorized off road scooter (see Figure 1). She was portrayed in three different visiting situations, driving the scooter through the garden pathway, reading a tag attached to a plant, and interacting with a child. The representation with the child may be interpreted as a desire to promote intergenerational family visits. The fact that the lady was mostly represented in full figure with the scooter at the forefront of the frame suggests the emphasis is on the equipment. One image depicted her slightly from above with a frontal point of view, looking directly at the viewer and smiling. According to social semiotic principles, such elements convey a meaning potential of engagement and equality with the viewer (Jewitt \& Rumiko, 2001). 


\section{[Insert Figure 1 around here]}

By comparison, the two pictures displayed by the Eden Project hinted at disability rather than actually showing it. One photo depicted a hand touching a tactile map; the other represented by a point of view from the back the blurred silhouettes of a man of a certain age pushing an elderly lady in a wheelchair on a marked pathway (age estimated based on clothing). These types of images may suggest the emphasis in on the sensory experience and onsite accessibility. However, because these images contrast with other photos found elsewhere on the website-which tended to show people and picture them smiling and interacting with others-they may leave an impression that the attraction providers appear to experience a degree of discomfort with the idea of including disability in visual marketing.

[Insert Table 3 around here]

\section{FMDs and the Marketing of Family Attractions}

The results of the qualitative content analysis on the inclusion of FMDs in marketing pointed to invisibility as a major theme. Indeed FMDs were generally not addressed by online marketing. None of the eight attractions provided textual or visual reference to FMDs or children with a disability in their homepage or web pages dedicated to accessibility or families. This implies that a FMD who wishes to visit these attractions needs to browse the websites for information on accessibility and on family-oriented experience, without obtaining a clear view of what is both suited to children and accessible. Given such invisibility, we directed our attention to how the family experience was represented on these websites in order to gain insight into the possible implication for FMDs. The sections devoted to family-oriented experiences focused on children both in text (i.e. lists of things to do with kids) and photos (i.e. most portrayed children with or without adults). Texts and images insisted on fun, physical activity and learning experiences for the children with expressions such as "adventure play" (Newquay Zoo), "to tire the most energetic little legs" (Lost Garden of Heligan), "designed to entertain and educate" (Eden Project). This message is consistent with previous research findings on parents viewing tourism as a time for physical activity and education (Southall, 2012). The analysis showed that the needs of children and adults were addressed separately, with few websites

highlighting the family togetherness experience in texts; an exception is Flambards' "great to experience as a family". Parents were most often referred to for their supervising role, as in Lanhydrock's: "Spend the day with your family at Lanhydrock. There's lots to keep children amused". 


\section{Discussion}

Despite some methodological limitations-including the fact that the research did not assess the accessibility of websites, and the accuracy of the information that is circulated through the mediums under scrutiny-our research sheds light on a variety of important issues with implications in terms of social sustainability and future research. A first issue concerns the factors determining the provision of access information. A second question is how PWDs are portrayed in tourism marketing, and what this tells us about tourism suppliers' perceptions of marketing to PWDs. A third issue is how current representations may affect social inclusion of PWDs, and the wider implications for social cohesion and social capital.

The study findings show how twenty years after the introduction of the DDA, and six years after the adoption of the Equality Act 2010, a sizeable proportion of visitor attraction suppliers in our study still fail to provide any access information either on printed materials $(55 \%)$ or on the internet (43\%). Doing so they fail to comply with the first and most basic dimension of inclusion: visibility (UNDESA, 2007). Others tended to limit their communication to a 'one box fits all' type, which does not provide the resources needed by PWDs to overcome the variety of environmental and socio-economic barriers to participation in tourism depending on their medical condition (Darcy et al., 2010; Figueiredo et al., 2012; Shaw \& Veitch, 2011). Availability of accessibility information was more frequent online than on paper, perhaps reflecting the greater space afforded by the internet but also its role as primary source of information for PWDs (Kastenholz et al., 2015). The study also found significant statistical differences in the marketing of accessibility relating to the organisation size and legal status. This finding certainly deserves further attention as there is currently little knowledge on the factors that enable or prevent the provision of accessibility information by tourist attraction providers. Our study strongly suggests that these factors might differ depending on the size and legal status of the organisation.

The use of imagery relating to disability in advertising was found to be sparse ( $0 \%$ of brochures, $4 \%$ of websites), reinforcing the impression of invisibility. The application of social semiotic principles has shown that, when available, images tend to have a representational meaning that either focuses on special equipment, or suggests some discomfort in portraying disability in visual marketing. Very few images depicted PWDs interacting with ABPs in a 'non carer-cared for' role, and 'enjoying the moment' situation (1 unit), or had an interactive meaning that directly engaged with the viewers (1 unit) (Kress \& van Leeuwen, 1996). Such representations inform us of the views of tourist attraction providers in how they perceive they should advertise to PWDs. In turn the effects of such representations would 
need to be confronted with those of marketing strategies that draw on affective attributes (Goossens, 2000) through images of an idealized reality (Xiang et al., 2008).

The representational techniques used with PWDs seem different from those used with ABPs, focusing more on basic needs (access) rather than on experience, and reflecting a more ambiguous position regarding the role the body should take. Despite the diffusion of practical guides (Visit England, n.d.a), there is still little understanding on how marketing for PWDs needs to be approached, with a need for research designs that include both PWDs and tourism suppliers, and takes the diversity of disability into consideration. It is not clear either, based on extant literature, whether PWDs should be regarded as a single market segment given the diversity of access needs (Darcy et al., 2010) and travel motives (Figueiredo et al., 2012).

With its supply-side focus, the study did not set out to produce knowledge on how these representations affect PWDs and FMDs in terms of social inclusion. However, such implications can be discussed based on the findings within the literature in terms of the information deficit and impacts on social stereotyping. The information deficit and the lack of inclusiveness in marketing may impinge on the pre-trip experience of PWDs with extensive planning (Foggin, 2011; Blichfeldt \& Nicolaisen, 2011) and potential fears of negative social interactions as a consequence of low disability awareness amongst tourism providers (Scholl et al, 2003). They also may reinforce social stereotypes of PWDs and ABPs, notably the minority status associated with disability (Borgerson and Schroeder, 2002; Nelson, 1999), and may affect PWDs' sense of belonging and self-acceptance (Edelheim, 2007), with possible impacts on their relatives. There is evidence that an FMD as any other families may reap wellbeing benefits from tourism (Lehto et al., 2009; Smith et al., 2009). However, there is little knowledge on pre-trip experience of FMDs, and the extent to which observations made in family tourism literature (e.g., Schänzel, 2012) also apply to FMDs. To fully grasp the effects of current tourism marketing on PWDs and their relatives there is a need for research on FMDs' pre-trip experiences, which takes into consideration the type of disability, which family member has the disability, as well as other mediums used by such families when planning their trips, including social media (Xiang et al., 2008) and acoustic advertising materials.

\section{Conclusions}

The study has examined three research objectives underlying the aim of social inclusion of PWDs in tourism. These objectives were investigated based on the case of visitor attractions in Cornwall, a major tourism destination in England. We found that, despite national and international recognition of the need for inclusion, PWDs' rights to access and participate in tourism in England-as in many 
other countries-remain dependent upon governmental priorities. Under neo-liberal ideologies and economic crises, such rights have been submitted to a return on investment, leading to watered-down implementation of actions to facilitate the inclusion of PWDs. Evidence of this is provided by the high proportion of Cornish visitor attractions failing to give any or complete information on access to PWDs. Most certainly, this shows that inclusion is an ethical objective that cannot be met without both appropriate legislation and policy enforcement.

Moreover, the study has shown that tourism marketing fails to address the broader objective of inclusion, notably by focusing on access and avoiding visual representations of disability in web sections that are not devoted to accessibility. Consequently, current tourism advertising often reduces PWDs to their impairments-which serve as a basis for market segmentation-and negates their needs for, and aspirations for, social interactions as individuals (of various age categories) and members of social groups, including families. This points to the need for further research on how marketing can better include PWDs in terms of segmentation and visual representations. There is evidence that PWDs have travel motives similar to those of ABPs (Blichfeldt \& Nicolaisen, 2011; Figueiredo et al., 2012); these include having quality time and visit experiences with the social and family units they are part of (Foggin, 2011). In conclusion there is an urgent need to gain additional knowledge on the conditions and modalities enabling shared experiences between ABPs and PWDs, including in the pre-trip phase, if tourism is to play its role in fostering social sustainability.

\section{References}

Agate, J., Zabriskie, R., Agate, S., \& Poff, R. (2009). Family leisure satisfaction and satisfaction with family life. Journal of Leisure Research, 41, 205-223.

Association of Leading Visitor Attractions (ALVA) (2016). Visits made in 2015 to visitor attractions in membership with ALVA, Retrieved from http://www.alva.org.uk/details.cfm?p=423

Barnes, C., \& Mercer, G. (2003). Disability. Cambridge: Polity.

Barnes, C., \& Mercer, G. (2010). Exploring Disability. $2^{\text {nd }}$ Ed. London: Polity Press.

Barthes, R. (1973). Mythologies. London: Paladin Books.

Beautort Research (2013). Cornwall Visitor Survey 2012. Report for Visit Cornwall.

Blichfeldt, B.S. (2008). What to do on our holiday: the case of in situ decision-making. Anatolia, 19(2), 5-23.

Blichfeldt, B.S., \& Nicolaisen, J. (2011). Disabled travel: not easy, but doable. Current Issues in Tourism, 14(1), 79-102. 
Borgerson, J., \& Schroeder, J. (2002). Ethical issues of global marketing: Avoiding bad faith in visual representations. European Journal of Marketing, 35, 570-594.

Burns, N, Paterson, K, \& Watson, N. (2009). An inclusive outdoors? Disabled people's experiences of countryside leisure services. Leisure Studies, 28, 403-417.

Jewitt, C., \& Rumiko, O. (2001). Visual meaning: a social semiotic approach. In: van Leeuwen \& Jewitt (eds.). The Handbook of Visual Analysis (pp.134-156), London: Sage.

Choia, S., Lehto, X., \& Morrison, A. (2007). Destination image representation on the web: Content analysis of Macau travel related websites. Tourism Management, 28, 118-129.

Conradson, D. (2005). Landscape, care and the relational self: Therapeutic encounters in rural England. Health \& Place, 11, 337-348.

Couch, G., Forrester, W. \& Mayhew-Smith, P. (1989). Access in London, London: Nicholson.

Dann, G. (1996). The people of tourist brochures. In T. Selwyn (Ed.), Tourist Image: Myths and Myth in Tourism (pp.61-82). West Sussex: Wiley.

Darcy, S., \& Buhalis, D. (2011). Conceptualising disability. In S. Darcy \& D. Buhalis (Eds.), Accessible Tourism: Concepts and Issues (pp.21-45). Bristol: Channel View.

Darcy, S., Cameron, B., \& Pegg, Sh. (2010). Accessible tourism and sustainability: a discussion and case study. Journal of Sustainable Tourism, 18, 515-537.

Darcy, S., Pegg. S, \& Cameron, B. (2011). Developing a business case for accessible tourism. In Darcy, S. \& Buhalis, D. (Eds.), Accessible Tourism: Concepts and Issues (pp.241-259). Bristol: Channel View.

Decrop, A. (2002). The influence of message format on the effectiveness of print advertisements for tourism destinations. International Journal of Advertising, 26, 505-525.

Disability Discrimination Act of 1995, UK. Retrieved from http://www.legislation.gov.uk/ukpga/ 1995/50/contents

Domínguez Vila, T., Darcy, S. \& Alén González, E. (2015). Competing for the disability tourism market - A comparative exploration of the factors of accessible tourism competitiveness in Spain and Australia. Tourism Management, 47, 261-272.

Dowling, M., \& Dolan, L. (2001). Families with children with disabilities: Inequalities and the social model. Disability and Society, 16, 21-35.

Edelheim, J. (2007). Hidden messages: A Polysemic reading of tourist brochures. Journal of Vacation Marketing, 13(5), 5-17.

Equality Act of 2010, UK [online]. Retrieved from http://www.legislation.gov.uk/ukpga/2010/ $15 /$ contents

Equality and Human Rights Commission (2010). The Equality Act: Guidance for businesses [online]. Retrieved from www.equalityandhumanright.com 
European Commission (2016). What is an SME? [online]. Retrieved from http://ec.europa.eu/growth/smes/business-friendly-environment/sme-definition

Eurostat (2012). Disability statistics - prevalence and demographics [online]. Retrieved from http://ec.europa.eu/eurostat/statistics-explained/index.php/Disability_statistics__prevalence_and_demographics

Figueiredo, E., Eusébio, C., \& Kastenholz, E. (2012). How diverse are tourists with disabilities? A pilot study on accessible leisure tourism experiences in Portugal. International Journal of Tourism Research, 14, 531-550.

Foggin, B. (2011). Tourism in the leisure lives of people with disability. In: D. Buhalis \& S. Darcy (Eds.). Accessible Tourism Concepts and Issues (pp.98-122). Bristol: Channel View.

Goldman, R. (1992). Reading Ads Socially. Abingdon: Routledge.

Google (2012). What is Google Custom Search [online]. Retrieved from https://developers.google.com/ custom-search

Goossens, C. (2000). Tourism information and pleasure motivation. Annals of Tourism Research, 27, 301-321.

Govers, R., \& Go, R. (2005). Projected destination image online: Website content analysis of pictures and text. Information Technology and Tourism, 7, 73- 89.

Gretzel, U., Yuan, Y.-L., \& Fesenmaier, D.R. (2000). Preparing for the new economy: Advertising Strategies and Change in Destination Marketing Organizations. Journal of Travel Research, 39, 146156.

Huff, C., Widmer, M., McCoy, K., \& Hill, B. (2003). The influence of challenging outdoor recreation on parent adolescent communication. Therapeutic Recreation Journal, 31, 18-37.

Hunter-Jones, P. (2011). The role of charities in social tourism. Current Issues in Tourism, 14(5), 445458.

Jewitt, C., \& Oyama, R. (2001). Visual meaning: a social semiotic approach. In: van Leeuwen, T. and Jewitt, C. (eds.) The Handbook of Visual Analysis (pp. 134-156). London: Sage.

Kastenholz, E., Eusébio, C., \& Figueiredo, E. (2015). Contributions of tourism to social inclusion of persons with disability. Disability \& Society, 30, 1259-1281.

Kress, G. \& van Leeuwen (1996). Reading Images: The Grammar of Visual Design. London: Routledge.

Lawlor, M.C., \& Elliot, M.L. (2012). Physical disability and body image in children. In: Cash, T.F. (ed.). Encyclopedia of Body Image and Human Appearance (vol. 2, pp. 650-656). London, UK: Elsevier.

Leask, A. (2010). Progress in visitor attraction research: towards more effective management. Tourism management, 31, 155-166. 
Lehto, X., Choi, S., Lin, Y-C., \& MacDermid, S. M. (2009). Vacation and family functioning. Annals of Tourism Research, 36(3), 459-479.

MacCannell, D. (1976). The Tourist, A New Theory of the Leisure Class. New York: Shocken books.

McCabe, S. \& Diekmann, A. (2015). The rights to tourism: reflections on social tourism and human rights. Tourism Recreation Research, 40(2), 194-204.

McCabe, S., \& Johnson,S. (2013). The happiness factor in tourism: Subjective well-being and social tourism. Annals of Tourism Research, 41, 42-65.

Michopoulou, E., \& Buhalis, D. (2011). Technology platforms and challenges. In: D. Buhalis \& S. Darcy (Eds.). Accessible Tourism Concepts and Issues (pp.287-299). Bristol: Channel View.

Morgan, N., \& Pritchard, A. (2000). Advertising in Tourism and Leisure. Oxford: Butterworth Heinemann, Oxford.

Murray, P. (2002). Hello! Are you listening? Disabled teenagers' experiences of access to inclusive leisure. York: Joseph Rowntree Foundation.

Nelson, J.A. (1999). Broken images: Portrayal of those with disabilities in American media. In: The disabled, the media, and the information age (pp. 1-17). Westport, CT: Greenwood.

Office for Disability Issues (2014, January). Disability facts and figures [online]. Retrieved from https://www.gov.uk/government/publications/disability-facts-and-figures/disability-facts-andfigures\#fnref:5

Pagán, R. (2015). The contribution of holiday trips to life satisfaction: the case of people with disabilities. Current Issues in Tourism, 18, 524-538.

Pan, B., Xiang, Z., Law, R., \& Fesenmaier, D. (2011). The dynamics of search engine marketing for tourist destinations. Journal of Travel Research, 50(4), 365-377.

Panofsky, E. (1970). Meaning in the Visual Arts, London: Penguin Books.

Purcell, K., Brenner, J., \& Rainie, L. (2012, March) Search engine use 2012. Washington, DC: The Pew Research Center's Internet and American Life Project. Retrieved from http://www.pewinternet.org/2012/03/09/search-engine-use-2012

Pühretmair, F., \& Nussbaum, G. (2011). Web design, assistive technologies and accessible tourism. In: D. Buhalis \& S. Darcy (Eds.). Accessible Tourism Concepts and Issues (pp.274-286). Bristol: Channel View.

Schänzel, H. (2012). Society and ideology: changes in family time perspections with implications for tourism. In H. Schänzel, I. Yeoman, \& E. Backer (Eds). Family Tourism: Multidisciplinary Perspectives (pp. 17-29). Bristol: Channel View.

Schänzel, H.A., \& Smith, K.A. (2013). The socialization of families away from home: Group dynamics and family functioning on holiday, Leisure Sciences, 36, 126-143. 
Scholl, K., McAvoy, L., Rynders, J., \& Smith, J. (2003). The influence of an inclusive outdoor recreation experiences on families that have a child with a disability. Therapeutic Recreation Journal, 37, 38-57.

Shapiro, J.P. (1993). No pity: People with disabilities forging a new civil rights movement. New York: Random House.

Shaw, G., \& Veitch, C. (2011). Demographic drivers of change in tourism and the challenge of inclusive products. In D. Buhalis \& S. Darcy (Eds.). Accessible Tourism Concepts and Issues (pp.160173). Bristol: Channel View.

Small, J., \& Darcy, S. (2011). Understanding tourist experience through embodiment: The contribution of critical tourism and disability studies. In D. Buhalis \& S. Darcy (Eds.). Accessible Tourism Concepts and Issues (pp.73-97). Bristol: Channel View.

Smith, K., Freeman, P., \& Zabriskie, R. (2009). An examination of family communication within the core and balance model of family leisure functioning. Family relations, 58, 79-90.

Southall, C. (2012). UK family tourism: Past, present and future challenges. In H. Schänzel, I. Yeoman, \& E. Backer (Eds). Family Tourism: Multidisciplinary Perspectives (pp. 50-66). Bristol: Channel View.

Stumbo, N. \& Pegg, S. (2005). Travellers and tourists with disabilities: A matter of priorities and loyalties, Tourism Review International, 8, 195-209.

UN Department of Economic and Social Affairs (UNDESA) (2007). Final report of the expert group meeting on creating an inclusive society. Practical strategies to promote social integration, Paris [online]. Retried from http://www.un.org/esa/socdev/egms/docs/2008/Paris-report.pdf

UN General Assembly (2006). Convention on the Rights of Persons with Disabilities: resolution, A/RES/61/10. United Nations, New York [online]. Retrieved on 28 April 2017 from http://www.ohchr.org/EN/HRBodies/CRPD/Pages/ConventionRightsPersonsWithDisabilities

UN World Tourism Organisations (UNWTO) (2016). UNWTO recommendations on accessible information in tourism [online]. Retrieved from http://www.eunwto.org/doi/pdf/ $10.18111 / 9789284417896$

Vallance, S., Perkins, H.C., and Dixon, J.E. (2011). What is social sustainability? A clarification of concepts. Geoforum, 342-348.

van Leeuwen, T. (2005). Introducing Social Semiotics. Abington, UK: Routledge.

Veitch, C., \& Shaw, G. (2004). Understanding barriers to tourism in the UK. Tourism Intelligence Papers, A185.

Veitch, C. \& Shaw, G. (2011). Disability legislation and empowerment of tourists with disability: The UK case. In D. Buhalis \& S. Darcy (Eds.). Accessible Tourism Concepts and Issues (pp.62-72). Bristol: Channel View.

Visit England (n.d.a). Destinations for all. A guide to creating accessible destinations [online]. Retrieved from https://www.visitbritain.org/sites/default/files/vb-corporate/dmo_guide_final.pdf 
Visit England (n.d.b). Winning more visitors. A guide for destination managers on providing access information on destination websites [online]. Retrieved from https://www.visitbritain.org/sites/default/files/vb-corporate/Documents-Library/documents/ England-documents/winning_more_visitors.pdf

Xiang, Z., Gretzel, U. \& Fesenmaier, D.R. (2009) Semantic Representation of Tourism on the Internet. Journal of Travel Research, 47(4), 440-453.

Xiang, Z., Wöber, K., \& Fesenmaier, D.R. (2008). Representation of the online tourism domain in search engines, Journal of Travel Research, 47(2), 137-150.

Yau, M.K., McKercher, B. \& Packer, T.L. (2004). Traveling with a disability. More than an access issue. Annals of Tourism Research, 31(4), 946-960.

Zabriskie, R. (2001). Family recreation: how can we make a difference? Parks and Recreation, 36(10), 30-42.

Zabriskie, R., \& McCormick, B. (2001). The influences of family leisure patterns on perceptions of family functioning. Family Relations, 50, 281-289.

Zabriskie, R., \& McCormick, B. (2003). Parent and child perspectives of family leisure involvement and satisfaction with family life. Journal of Leisure Research, 35, 163-189. 